\title{
Involvement of jasmonic acid, ethylene and salicylic acid signaling pathways behind the systemic resistance induced by Trichoderma longibrachiatum H9 in cucumber
}

\author{
Min Yuan ${ }^{1 \dagger}$, Yuanyuan Huang ${ }^{2+}$, Weina Ge ${ }^{1}$, Zhenhua Jia $^{2}$, Shuishan Song ${ }^{2}$, Lan Zhang ${ }^{1}$ and Yali Huang ${ }^{2 *}$
}

\begin{abstract}
Background: Trichoderma spp. are effective biocontrol agents for many plant pathogens, thus the mechanism of Trichoderma-induced plant resistance is not fully understood. In this study, a novel Trichoderma strain was identified, which could promote plant growth and reduce the disease index of gray mold caused by Botrytis cinerea in cucumber. To assess the impact of Trichoderma inoculation on the plant response, a multi-omics approach was performed in the Trichoderma-inoculated cucumber plants through the analyses of the plant transcriptome, proteome, and phytohormone content.

Results: A novel Trichoderma strain was identified by morphological and molecular analysis, here named $T$. longibrachiatum H9. Inoculation of $\mathrm{T}$. Iongibrachiatum H9 to cucumber roots promoted plant growth in terms of root length, plant height, and fresh weight. Root colonization of $T$. longibrachiatum H9 in the outer layer of epidermis significantly inhibited the foliar pathogen B. cinerea infection in cucumber. The plant transcriptome and proteome analyses indicated that a large number of differentially expressed genes (DEGs) and differentially expressed proteins (DEPs) were identified in cucumber plants $96 \mathrm{~h}$ post T. longibrachiatum H9 inoculation. Up-regulated DEGs and DEPs were mainly associated with defense/stress processes, secondary metabolism, and phytohormone synthesis and signaling, including jasmonic acid (JA), ethylene (ET) and salicylic acid (SA), in the T. longibrachiatum H9-inoculated cucumber plants in comparison to untreated plants. Moreover, the JA and SA contents significantly increased in cucumber plants with T. longibrachiatum H9 inoculation.

Conclusions: Application of T. longibrachiatum $\mathrm{H} 9$ to the roots of cucumber plants effectively promoted plant growth and significantly reduced the disease index of gray mold caused by $B$. cinerea. The analyses of the plant transcriptome, proteome and phytohormone content demonstrated that $T$. Iongibrachiatum $\mathrm{H} 9$ mediated plant systemic resistance to $B$. cinerea challenge through the activation of signaling pathways associated with the phytohormones JA/ET and SA in cucumber.
\end{abstract}

Keywords: Cucumber, Trichoderma longibrachiatum, Botrytis cinerea, Transcriptome, Proteome, Defense response, Phytohormones, Secondary metabolites

\footnotetext{
* Correspondence: huangyali2291@163.com

${ }^{\dagger}$ Min Yuan and Yuanyuan Huang contributed equally to this work.

${ }^{2}$ Biology Institute, Hebei Academy of Sciences, Shijiazhuang 050081, People's

Republic of China

Full list of author information is available at the end of the article
}

(c) The Author(s). 2019 Open Access This article is distributed under the terms of the Creative Commons Attribution 4.0 International License (http://creativecommons.org/licenses/by/4.0/), which permits unrestricted use, distribution, and

reproduction in any medium, provided you give appropriate credit to the original author(s) and the source, provide a link to the Creative Commons license, and indicate if changes were made. The Creative Commons Public Domain Dedication waiver (http://creativecommons.org/publicdomain/zero/1.0/) applies to the data made available in this article, unless otherwise stated. 


\section{Background}

Botrytis cinerea is a necrotrophic fungal pathogen that infects more than 200 commercial crops, leading to significant agricultural losses worldwide [1]. To date, chemical fungicides remain the primary method of controlling this pathogen. Due to the detrimental effects on the environment and potential risks for human health of chemical fungicides, a biocontrol method would constitute a preferable alternative approach [2]. Trichoderma spp. are plant growth-promoting fungi that have been found to have great potential for the control of gray mold caused by B. cinerea [3, 4]. The biocontrol can be achieved by a direct interaction between Trichoderma and pathogens, or indirectly by inducing plant resistance to pathogens in the same or different parts from the pathogen infection sites. Traditionally, Trichoderma spp. directly antagonize pathogens by mycoparasitism, secretion of antibiotics, and competition for space and nutrients [5-7]. However, subsequent discoveries have demonstrated that these biocontrol agents can also interact intimately with plant roots, even colonizing the outer epidermal layers, and act as avirulent, opportunistic plant symbionts [3, 7]. Root colonization by selected Trichoderma isolates has been reported to promote plant growth and increase resistance to a variety of pathogens, both soil-borne and foliar, in various plant species [8-12]. Although the mechanism of induced plant resistance is not fully understood, the plant response to Trichoderma spp. has been studied at the physiological and biochemical levels. These studies have shown that colonization by Trichoderma spp. triggers a series of plant responses that may enhance the defensive capacity of the plant. Mitogen-activated protein kinase (MAPK) cascades are activated in Arabidopsis thaliana leaves by inoculation of the roots with T. hamatum T382 [8]. The cucumber MAPK homologous to A. thaliana MPK3 is induced by incubation of the roots with $T$. asperellum T203 [13]. Activation of MAPK cascades will alter the phosphorylation status of many substrate proteins to regulate diverse downstream signaling pathways, such as phytohormone signaling [14]. Plant hormone signaling may modulate the defense network by translating Trichoderma-induced upstream signaling events into the activation of defense responses.

In the past, researchers found that contacting with pathogenic and non-pathogenic organisms would trigger two main defense mechanisms in plants: systemic acquired resistance (SAR) and induced systemic resistance (ISR). SAR is commonly triggered by local pathogen attack, correlating with the involvement of salicylic acid (SA) and the activation of PR genes. ISR is activated when the plant interacts with non-pathogenic rhizosphere fungi or bacteria, and requires jasmonic acid (JA)/ethylene (ET) [10, 15]. However, the traditional knowledge of ISR became controversial in recent years. Increasing research has demonstrated that Trichoderma may induce systemic resistance through multiple hormonal signaling pathways, and the specific hormones involved are dependent on both the plant species and Trichoderma strains involved. The cross-talk among different hormone signaling pathways may render plants capable of finely regulating immune responses $[8,10$, 15-23]. It has also been demonstrated that Trichoderma spp. can positively interfere with reactive oxygen species (ROS) production, e.g., through increasing the ROS scavenging ability of the plant at future infection sites, thereby potentially reducing the damaging levels of ROS in the leaves, thus limiting B. cinerea infection [24-27]. The expression of defense-related proteins can be strongly potentiated when plants are challenged by additional pathogens, even at sites distant from the location of Trichoderma colonization [3]. Along with other defense strategies, the production of secondary metabolites, such as phytoalexins, plays important roles in the plant defense against $B$. cinerea [26, 28-32]. Collectively, it is likely that Trichoderma spp. induce multiple levels of changes in plant metabolism that can lead to increased resistance to abiotic and biotic stresses, and thus the mechanism of Trichoderma-induced systemic resistance requires further investigation [33].

Cucumber is one of the most economically important vegetables worldwide. It is susceptible to infection by the plant-pathogenic fungus $B$. cinerea. Finding potential biocontrol Trichoderma spp. against cucumber diseases is thus warranted [34, 35]. In this study, a novel Trichoderma strain was identified, namely $T$. longibrachiatum H9, which could promote plant growth and reduce the disease index of gray mold caused by $B$. cinerea in cucumber. Furthermore, the effect of $T$. longibrachiatum $\mathrm{H} 9$ on induction of defense response in cucumber plants was studied through the analyses of the plant transcriptome, proteome and phytohormone content. The large-scale, multi-omics datasets allowed us to monitor changes in cucumber gene and protein expressions and also provided a basis from which to illustrate the biocontrol mechanism of $T$. longibrachiatum H9 induced systemic resistance against $B$. cinerea.

\section{Methods}

\section{Morphological and molecular identification of the novel strain}

The Trichoderma H9 strain was grown on potato dextrose agar (PDA) medium at $30^{\circ} \mathrm{C}$ and identified by morphological observation based on the monograph of Gams and Bisset [36]. The spores were harvested by flooding the surface of the cultures with distilled water. One milliliter of spore suspension was aliquoted and inoculated into potato-dextrose (PD) broth in a rotary 
shaker at $30{ }^{\circ} \mathrm{C}$ and $200 \mathrm{rpm}$ for $48 \mathrm{~h}$. The mycelium was collected by filtration and washed three times with distilled water. Genomic DNA was extracted using a commercial DNA extraction kit. Using the Trichoderma strain H9 genome as the template, the ITS and TEF- $1 \alpha$ genes were amplified using specific primers, which were described in Additional file 1: Table S1 (ITS4 and ITS6 for ITS, as well as EF1-728F and TEF1-LLErev for TEF-1 $\alpha$ ). The PCR products were then sequenced by the Sangon Biotechnology Co., Ltd. Shanghai, China. The ITS and TEF- $1 \alpha$ sequences of this strain were deposited in GenBank with the accession numbers MF111118 and MK179408 respectively, and were then aligned with the corresponding sequences of known Trichoderma strains using NCBI BLAST. The phylogenetic trees were constructed under Maximum Likelihood method using MEGA 7 software [37] based on the ITS or TEF-1 $\alpha$ sequences. The phylogeny tests were evaluated through performing 1000 bootstrap replicates.

\section{Plant growth, Trichoderma inoculation and pathogen challenge}

Seeds of cucumber (Cucumis sativus L.) were purchased from Tianjin Kernel Cucumber Research Institute (Tianjin, China). The seeds were sterilized in $70 \%$ ethanol for $2 \mathrm{~min}, 2.0 \% \mathrm{NaOCl}$ for $2 \mathrm{~min}$, washed with sterile water three times, and then placed on a sterile gauze sheet with liquid $1 / 2$ Murashige and Skoog (MS) medium in a Petri dish at $37^{\circ} \mathrm{C}$ for $24 \mathrm{~h}$. Germinated seeds (30 per box) were placed on a sterile gauze sheet on top of a sterile steel screen in a $50 \times 25 \times 8$ (depth) $\mathrm{cm}$ pot system under a $12 \mathrm{~h}$ light $/ 12 \mathrm{~h}$ dark cycle at $25 \pm 2{ }^{\circ} \mathrm{C}$ with a light intensity of $120 \mu \mathrm{mol} / \mathrm{m}^{2} \mathrm{~s}$. The steel screen holds the seeds $1 \mathrm{~cm}$ above the liquid medium [38].

Trichoderma inoculation was performed when the plants had grown to the 3-leaf stage, at which point the spore suspension of Trichoderma H9 at a final concentration $1 \times 10^{6} \mathrm{cfu} / \mathrm{mL}$ was added to the pot. ${ }^{1} / 2 \mathrm{MS}$ medium was used instead of spore suspension in the control group.

The $B$. cinerea challenge was performed $24 \mathrm{~h}$ post $\mathrm{H} 9$ inoculation ( $24 \mathrm{hpTi})$. Ten microliters of $B$. cinerea spore suspension at a concentration of $1 \times 10^{8} \mathrm{cfu} / \mathrm{mL}$ was injected into the abaxial surface of the cucumber leaves. Water was injected as the control for the $B$. cinerea challenge. In total, four different treatment groups were established, namely non-inoculated, non-challenged plants (-T-B), non-inoculated, challenged plants $(-T+B)$, inoculated, non-challenged plants $(+\mathrm{T}-\mathrm{B})$, and inoculated, challenged plants $(+\mathrm{T}+\mathrm{B})[10]$.

\section{Detection of promoting effect on plant growth}

The method for Trichoderma plant inoculation was described above. Thirty plants were used for each treatment.
Treated plants were placed under a $12 \mathrm{~h}$ light $/ 12 \mathrm{~h}$ dark cycle at $25 \pm 2{ }^{\circ} \mathrm{C}$. After two weeks, the plants were harvested and the root length, plant height and fresh weight were measured. Three replicates were performed.

\section{Detection of biocontrol efficacy}

The method for Trichoderma plant inoculation and $B$. cinerea challenge was described above in the $-\mathrm{T}+\mathrm{B}$ and $+\mathrm{T}+\mathrm{B}$ groups. Three different sites per leaf were selected on the second and third leaves of each plant. Twelve plants for each group were treated. Three replicates were performed. Following treatment, the cucumber plants were grown under a $12 \mathrm{~h}$ light $/ 12 \mathrm{~h}$ dark cycle at $25 \pm 2{ }^{\circ} \mathrm{C}$. The disease severity of the gray mold was recorded daily. When $B$. cinerea broadly infected the cucumber leaves in the $-\mathrm{T}+\mathrm{B}$ group, the disease index and inhibition rate were calculated according to the standard for gray mold disease progression. The disease progression of the infected plants was divided into five grades, where grade $0=$ no visible gray mold spot, grade $1=1-$ $5 \%$, grade $3=6-15 \%$, grade $5=16-25 \%$, grade $7=26-$ $50 \%$, and grade $9=\geq 51 \%$ of the leaf surface covered with gray mold. The gray mold development on each plant was recorded using the above 1-5 scale, and the disease index was calculated using the following formula [39]:

$$
\begin{aligned}
& \text { Disease index }= \begin{aligned}
\Sigma & (\text { number of leaves in each disease grade } \\
& \times \text { grades value }) /(\text { total number of assessed leaves } \\
& \times \text { the highest grade value })
\end{aligned} \\
& \begin{aligned}
\text { Disease inhibition rate }(\%)= & \text { (disease index of control } \\
& - \text { disease index after treatment }) \\
& / \text { disease index of control } \times 100
\end{aligned}
\end{aligned}
$$

\section{Sample processing for transmission electron microscopic study}

Cucumber root samples (4 to $10 \mathrm{~mm}$ ) were collected from the main root at the Trichoderma penetration sites, 96 hpTi. Samples were treated and then examined in a Hitachi H-7650 transmission electron microscope as described [31, 38]. The sites of root colonization by Trichoderma were characterized by comparing the samples from Trichoderma-inoculated and non-inoculated groups. Five samples from five different roots for each group, and 10 ultrathin sections for each sample were observed.

\section{Statistical analysis}

Statistical analysis was performed using SPSS software, version 20.0 (SPSS, Inc., Chicago, IL, US). The data from plant growth promoting assays, biocontrol efficacy and plant hormones measurement assays were analyzed by one-way analysis of variance (ANOVA), and the statistical significance was determined using pair-wise comparisons $(P<0.05)$. 


\section{Transcriptome analysis by RNA-Seq}

The second and third cucumber leaves were collected from the $-\mathrm{T}-\mathrm{B}$ and $+\mathrm{T}-\mathrm{B}$ groups at $96 \mathrm{hpTi}$ respectively when the plants in the $+\mathrm{T}+\mathrm{B}$ group showed a clear inhibition of $B$. cinerea infection. The samples were immediately frozen in liquid nitrogen, and then sent to Shanghai Biotechnology Co., Ltd. Shanghai, China for RNA sequencing. The reference genome for transcriptome analysis was acquired from ftp://cucurbitgenomics.org/pub/cucurbit/genome/cucumber/Chinese_long/v2/. Three biological replicates in each group were performed and raw data were deposited into the Sequence Read Archive database with the accession number SRP136435. A basic analysis was performed on the transcriptome data, including data pre-processing, genomic mapping, gene expression analysis, analysis of differentially expressed genes (DEGs), and Gene Ontology (GO)/Kyoto Encyclopedia of Genes and Genomes (KEGG) enrichment analysis of DEGs. Gene expression levels were determined by FPKM (Fragments Per Kilobase of exon model per Million mapped reads) as described [40]. In order to screen DEGs, up- and down-regulation of genes was defined when the adjusted $P$-value was $<0.05$ and the absolute fold change was $\geq 2.0$ ( $\left|\log _{2}{ }^{\text {(fold change) }}\right| \geq 1.0$ ). Regarding the GO/KEGG enrichment analysis, $P$-value $<0.05$ was chosen as the standard to determine enrichment.

\section{Translatome analysis by iTRAQ mass spectrometry}

The second and third cucumber leaves were collected from the -T-B and + T-B groups at $96 \mathrm{hpTi}$, and immediately frozen in liquid nitrogen, respectively, and then sent to Allwegene Technology Inc. Beijing, China for iTRAQ sequencing. Raw data related to this study have been deposited into iProX (ww.iprox.org) with ID IPX0001185000/PXD009314. Protein identification was performed using the ProteinPilot ${ }^{\mathrm{TM}}$ v4.5 search engine against a database (Uniprot Cucumis sativus L). Only peptides with an unused score $\geq 1.3$ and confidence interval $>95 \%$ were counted to reduce the probability of false peptide identification. Each confident protein was identified with at least one unique peptide. Furthermore, differentially expressed proteins (DEPs) were screened by iTRAQ quantification and up- and down-regulation of proteins was defined when the $P$-value was $<0.05$ and the absolute fold change was $\geq 2.0$. GO/KEGG enrichment analyses of differentially expressed proteins (DEPs) for functional annotations were further performed, and $P$-value $<0.05$ was selected as the standard to determine the enrichment.

\section{Correlation analysis between transcriptome and proteome data}

The expression trends of the genes from the transcriptome analysis and their corresponding proteins from the proteome analysis were compared as described [41]. The results were divided into three categories: correlated genes/Proteins, DEGs/DEPs with corresponding proteins/genes, and DEGs/DEPs with corresponding DEPs/ DEGs. Correlated DEGs/DEPs were further divided into two categories: with the same expression trend and the opposite expression trend.

\section{Plant hormones measurement}

The same treatment groups were established (-T-B and $+\mathrm{T}-\mathrm{B})$ as in the previous experiments. The cucumber leaves were harvested from each group at $96 \mathrm{hpTi}$, and the SA and JA contents were measured using HPLC/ MS/MS (high performance liquid chromatography tandem mass spectrometry), which was performed by Zoonbio Biotechnology Co., Ltd. Nanjing, China. Samples were separated by Agilent1290 Infinity liquid chromatography from Agilent (Santa Clara, CA, US) and analyzed by QTrap 6500 mass spectrometer from AB Sciex (Framingham, MA, US) as described [42]. Three replicates were performed.

\section{Quantitative real-time (qRT-PCR) analysis marker gene expression}

Leaf tissue was collected from the second and third cucumber leaf in the -T-B and + T-B groups at $96 \mathrm{hpTi}$, respectively. Total RNA was extracted from each sample using RNAiso ${ }^{\mathrm{Tm}}$ Plus reagents according to the manufacturer's instructions. The cDNA synthesis and qRT-PCR were performed according to the PrimeScript ${ }^{\mathrm{m}} \mathrm{RT}$ reagent kit. Specific primers used in the qRT-PCR were described in Additional file 1: Table S1. Expression values were normalized to the ACT2 gene. The experiments were repeated three times.

\section{Results \\ Morphological and molecular identification of the Trichoderma $\mathrm{H} 9$ strain}

The Trichoderma H9 strain was obtained from the soil near a cucumber plant and exhibited the typical morphological features of $T$. longibrachiatum based on the monograph of Gams and Bisset [36]. Molecular identification based on ITS and TEF- $1 \alpha$ genes revealed that this H9 strain shared the highest homology in the phylogeny and clustered together with $T$. longibrachiatum strains, whose species identity has been confirmed by phylogenetic analysis [43-47]. The H9 strain was thus identified to be $T$. longibrachiatum, and was accordingly named $T$. longibrachiatum $\mathrm{H} 9$.

\section{Plant growth enhancement by T. longibrachiatum H9 inoculation in cucumber plants}

Furthermore, growth-promoting effects by $T$. longibrachiatum H9 inoculation were observed based on root length, plant height, and fresh weight measurements of 
the cucumber plants. The average root length, plant height, and fresh weight of the $T$. longibrachiatum H9-inoculated plants were $7.46 \pm 0.35 \mathrm{~cm}, 3.79 \pm 0.07$ $\mathrm{cm}$, and $48.63 \pm 1.88 \mathrm{~g}$, which were significantly higher than those of untreated plants with $5.02 \pm 0.16 \mathrm{~cm}, 3.42$ $\pm 0.11 \mathrm{~cm}$, and $38.16 \pm 1.53 \mathrm{~g}$, respectively $(P<0.05)$. The T. longibrachiatum $\mathrm{H} 9$ strain significantly impacted root length (48.68\%), plant height (10.82\%), and fresh weight (27.44\%) in cucumber (Table 1).

\section{Biocontrol effects by $T$. longibrachiatum $\mathrm{H} 9$ against $B$. cinerea}

In order to determine if T. longibrachiatum H9 could reduce the symptoms of $B$. cinerea infection in cucumber, 3-leaf stage cucumber plant roots were treated with T. longibrachiatum $\mathrm{H} 9$ and their susceptibility to $B$. cinerea $(+\mathrm{T}+\mathrm{B})$ leaf infection was subsequently assessed by comparison to mock-treated plants $(-\mathrm{T}+\mathrm{B})$. Treatment of cucumber with $T$. longibrachiatum H9 significantly reduced the disease index after 4,8 , and $12 \mathrm{~d}$, and the inhibition rates increased to $56.7 \%$ on the 12 th day from $49.62 \%$ on the 4 th day $(P<0.05$; Table 2$)$.

Consistently, T. longibrachiatum H9 penetrated cucumber root cortical cells and was restricted in the out layer of epidermis after $96 \mathrm{~h}$ (96 hpTi), which allowed sufficient time for spore germination, colonization of the roots and induction of a plant response. A large number of Trichoderma hyphae developed at the root surface (RS) (Fig. 1a), penetrated into the root epidermis (EP) (Fig. 1b) and progressed towards the cortex (CO) (Fig. 1c), mainly by intercellular growth. The mycelia of $T$. longibrachiatum H9 grew mainly between the cells and thickened the cell wall without entering the cell, as observed by transmission electron microscopy. Taken together, the biocontrol assays indicated that root colonization by $T$. longibrachiatum $\mathrm{H} 9$ may induce systemic disease resistance against the foliar pathogen B. cinerea in cucumber.

\section{Deciphering the plant responses associated with $T$. longibrachiatum $\mathrm{H} 9$ inoculation using transcriptome analysis and ITRAQ proteomics}

To examine the underlying mechanisms of the plant response associated with $T$. longibrachiatum $\mathrm{H} 9$-induced plant resistance, both RNA-Seq and proteome analysis were performed on cucumber plant samples harvested at $96 \mathrm{hpTi}$ from the $-\mathrm{T}-\mathrm{B}$ and $+\mathrm{T}-\mathrm{B}$ groups, respectively. Compared to untreated plants (+T-B vs. -T-B), 3765 DEGs were identified from the RNA-Seq analysis, with
2304 up-regulated genes and 1461 down-regulated genes under T. longibrachiatum H9 inoculation. A total of 922 DEPs were identified from the proteome analysis with 428 up-regulated and 494 down-regulated proteins $(P<0.05$ and fold change $>2.0$; Table 3$)$. GO enrichment and KEGG enrichment analyses were further performed to classify the up-regulated and down-regulated DEGs and DEPs.

Based on up-regulated DEGs or DEPs, biological processes was the most enriched category and the GO terms related to phytohormones, secondary metabolism and defense/stress processes were significantly enriched $(P<$ $0.05)$. The biosynthesis and signaling of hormones, including JA/ET and SA, were observed as plant responses in the plant hormones category. "Phenylpropanoid biosynthetic process", "flavonoid biosynthetic process", "lignin biosynthetic process" and other secondary metabolic processes were identified in the secondary metabolites category. Many GO terms related to defense/stress processes were observed including "defense response", "response to oxidative stress", "response to reactive oxygen species", and so on. Meanwhile, several signal transduction GO terms were observed, such as "MAPK cascade" and "signal transduction by protein phosphorylation" $(P<$ 0.05; Additional file 2: Table S2, Additional file 3: Table S3). Based on down-regulated DEGs or DEPs, "photosynthesis" and "photosynthesis, light reaction" were significantly enriched terms $(P<0.05$; Additional file 4: Table S4, Additional file 5: Table S5).

The KEGG enrichment analysis allowed us to identify specific pathways according to DEGs or DEPs, respectively. The pathways related to the biosynthesis of phytohormones, including "phenylalanine metabolism (SA biosynthesis)", "alpha-linolenic acid metabolism (JA biosynthesis)", and "cysteine and methionine metabolism (ET biosynthesis)", were significantly enriched based on up-regulated DEGs or DEPs, respectively. Moreover, the pathways "phenylpropanoid biosynthesis", "flavonoid biosynthesis", "MAPK signaling pathway" and "peroxisome pathway", which are associated with secondary metabolite biosynthesis, signal transduction, or defense/stress processes, were also activated in the $T$. longibrachiatum H9-inoculated cucumber plants $(P<0.05$; Additional file 6: Table S6, Additional file 7: Table S7). The top 20 enriched KEGG pathways based on up-regulated DEGs or DEPs were shown, respectively (Figs. 2 and 3). The presence of T. longibrachiatum H9 reprogrammed the gene and protein expression related to phytohormones, secondary

Table 1 Inoculation of T. longibrachiatum H9 to cucumber roots effectively promoted cucumber plant growth

\begin{tabular}{lllllll}
\hline Strains & Root length $(\mathrm{cm})$ & Increase rate $(\%)$ & Plant height $(\mathrm{cm})$ & Increase rate $(\%)$ & Fresh weight $(\mathrm{g})$ & Increase rate $(\%)$ \\
\hline $\mathrm{H} 9$ & $7.46 \pm 0.35^{*}$ & 48.68 & $3.79 \pm 0.07^{*}$ & 10.82 & $48.63 \pm 1.88^{*}$ & 27.44 \\
Control & $5.02 \pm 0.16$ & - & $3.42 \pm 0.11$ & - & $38.16 \pm 1.53$ & -
\end{tabular}

Note: * and ${ }^{*}$ indicate significance at $P<0.05$ and 0.01 
Table 2 Treatment of cucumber with T. longibrachiatum H9 significantly reduced the disease index of gray mold

\begin{tabular}{|c|c|c|c|c|c|c|}
\hline \multirow[t]{3}{*}{ Groups } & \multicolumn{6}{|c|}{ Days after H9 inoculation } \\
\hline & \multicolumn{2}{|l|}{$\overline{4 d}$} & \multicolumn{2}{|l|}{$8 d$} & \multicolumn{2}{|l|}{$12 \mathrm{~d}$} \\
\hline & Disease index & Inhibition rate $\%$ & Disease index & Inhibition rate\% & Disease index & Inhibition rate\% \\
\hline$-T+B$ & $0.339 \pm 0.028$ & - & $0.465 \pm 0.042$ & - & $0.530 \pm 0.011$ & - \\
\hline$+T+B$ & $0.267 \pm 0.036^{*}$ & 49.62 & $0.234 \pm 0.016^{*}$ & 55.85 & $0.213 \pm 0.017^{*}$ & 56.7 \\
\hline
\end{tabular}

Note: ${ }^{*}$ and ${ }^{* *}$ indicate significance at $P<0.05$ and 0.01

metabolism, and defense/stress processes in cucumber plants. This suggested that T. longibrachiatum H9 inoculation might enhance plant defense capacity through activating the signaling pathways associated with the phytohormones JA/ET and SA.

\section{Correlation analysis of transcriptome and proteome data} To further explore the findings from both transcriptome and proteome data, the correlation analysis was performed by comparing the expression trends of the genes from the transcriptome analysis and their corresponding proteins from the proteome analysis. 3938 genes/proteins were correlated in the totally detected 4171 proteins and 20,189 genes. Among the 3765 DEGs/922 DEPs, 798 DEGs/835 DEPs showed corresponding proteins/genes, and 277 DEGs/DEPs showed corresponding DEPs/DEGs. Furthermore, 241 DEGs/DEPs showed the same expression trends with 132 DEGs/DEPs up-regulated and 109 DEGs/DEPs down-regulated (Table 4, Additional file 8: Table S8). The enriched KEGG pathways based on the 132 up-regulated DEGs/DEPs were analyzed and the top 20 pathways were shown (Fig. 4). "Phenylalanine metabolism (SA biosynthesis)", "alpha-linolenic acid metabolism (JA biosynthesis)", "cysteine and methionine metabolism (ET biosynthesis)", "biosynthesis of secondary metabolites", "phenylpropanoid biosynthesis", and "peroxisome" pathways were remain significantly enriched. In contrast, "ribosome", "porphyrin and chlorophyll metabolism"and "photosynthesis" were the most significantly enriched pathways based on the 109 down-regulated DEGs/DEPs (Additional file 9: Figure S1).

\section{Confirmation of qRT-PCR}

To evaluate the transcriptome results, several genes in the hormone pathways were selected for qRT-PCR analysis in the $-\mathrm{T}-\mathrm{B}$ and $+\mathrm{T}-\mathrm{B}$ groups at $96 \mathrm{hp}$. Ti, such as LOX1,LOX2, and AOS1 associated with JA, PAD4 associated with $\mathrm{SA}$, as well as $A C O$ associated with ET. The expression of these genes was significantly up-regulated in the $+\mathrm{T}-\mathrm{B}$ group, compared to that in the -T-B group (Fig. 5).

\section{JA and SA content analysis}

Based on the transcriptome and proteome results, the key enzymes in JA and SA biosynthesis were up-regulated at both the RNA and protein levels. Therefore, the JA and SA contents in cucumber leaves were analyzed in the $-\mathrm{T}-\mathrm{B}$ and $+\mathrm{T}-\mathrm{B}$ groups at $96 \mathrm{hpTi}$. The SA content increased to $137.29 \pm 1.8120 \mathrm{ng} / \mathrm{g}$, and the JA content rose to $151.45 \pm 0.0403 \mathrm{ng} / \mathrm{g}$ in the $+\mathrm{T}$-B group (Table 5). The JA and SA contents significantly increased in the $T$. longibrachiatum H9-inoculated cucumber plants, compared to that in the untreated plants. These results
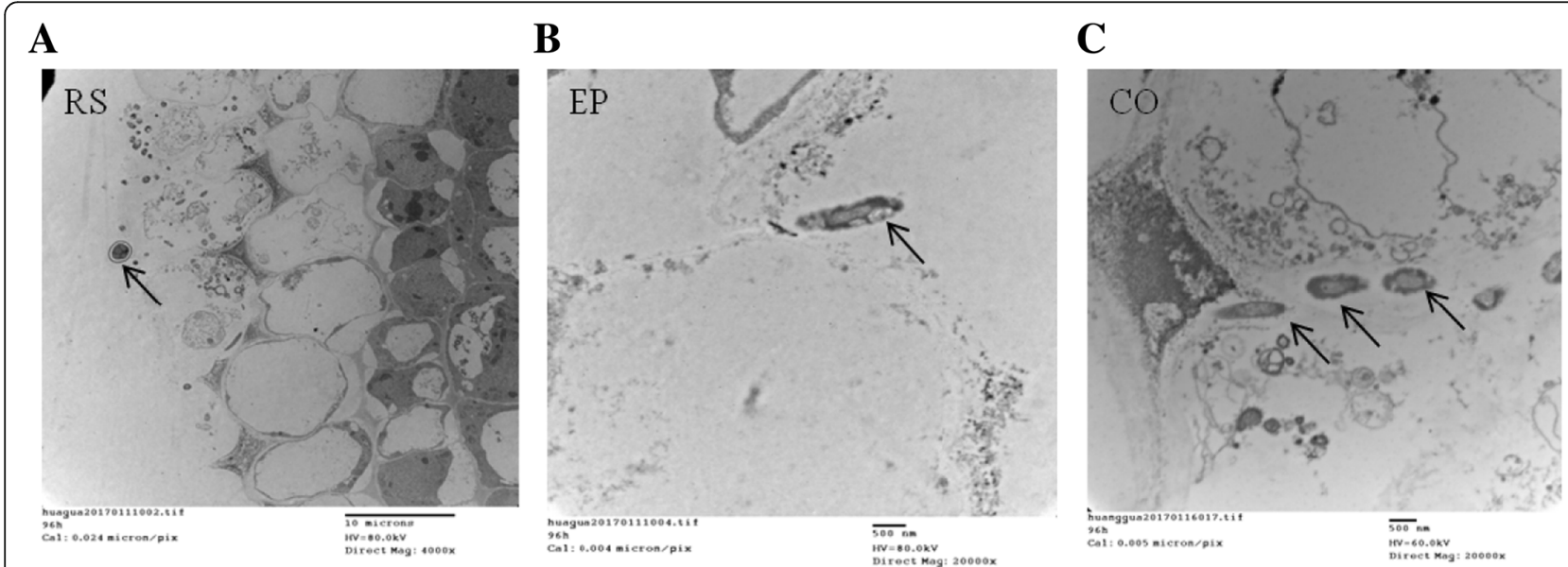

Fig. 1 Transmission electron micrographs indicated that T. longibrachiatum H9 had colonized the cucumber roots. Trichoderma hyphae developed at the root surface (a), penetrated into the root epidermis (b), and progressed towards the cortex (c). Arrows indicate Trichoderma hyphae. Bars: A, 10 um; B, $500 \mu \mathrm{m} ; \mathrm{C}, 500 \mu \mathrm{m}$ 
Table 3 Summary of the number of DEGs and DEPs detected in the T. longibrachiatum H9-inoculated cucumber plants, compared to untreated plants (+T-B vs. -T-B)

\begin{tabular}{lll}
\hline & Genes & Proteins \\
\hline Total DEGs/DEPs & 3765 & 922 \\
Up-regulated & 2304 & 428 \\
Down-regulated & 1461 & 494 \\
\hline
\end{tabular}

implied that JA and SA played important roles in regulating the plant response and enhancing plant defense in cucumber plants with T. longibrachiatum H9 inoculation.

\section{Discussion}

In this study, we demonstrated that inoculation of $T$. longibrachiatum $\mathrm{H} 9$ to the cucumber roots triggered an increased resistance to the leaf pathogen $B$. cinerea, which is characterized by the reduction of the disease incidence. The effect of $T$. longibrachiatum H9 on induction of defense response was monitored through both the transcriptome and proteome analyses. More specifically, further comparison and analysis of transcriptome and proteome data provided a more reliable basis to illustrate the biocontrol mechanism of $T$. longibrachiatum
H9 induced systemic resistance against $B$. cinerea. Finally, the following conclusions could be drawn by analyzing our findings and the earlier findings from other researchers.

\section{Plants respond to Trichoderma by hormone production or signaling}

It is known that phytohormones play an important role in the regulation of defense responses in plants. Generally, ISR induced by non-pathogen organisms relies on JA signaling, while pathogen-induced SAR is dependent on SA signaling. In recent years, many reported studies have demonstrated that multiple hormones may be involved in shaping ISR [8, 10, 15-23]. Thus, the current view on the specific hormones involved in ISR remains controversial, and the mechanism of ISR seems more complicated. Mathys et al. (2012) found that the SA pathway was a first player in the T. hamatum T382-triggered ISR-prime in A. thaliana, and SA was synthesized from chorismate rather than phenylalanine. The JA-pathway was not activated at $48 \mathrm{hp}$. Ti in the $T$. hamatum T382-preinoculated plants without a subsequent infection, and $B$. cinerea challenge caused a clear activation of the JA pathway for ISR-boost [8]. Meanwhile they defined ISR-prime phase as the process of the

\section{KEGG pathways (Top 20)}

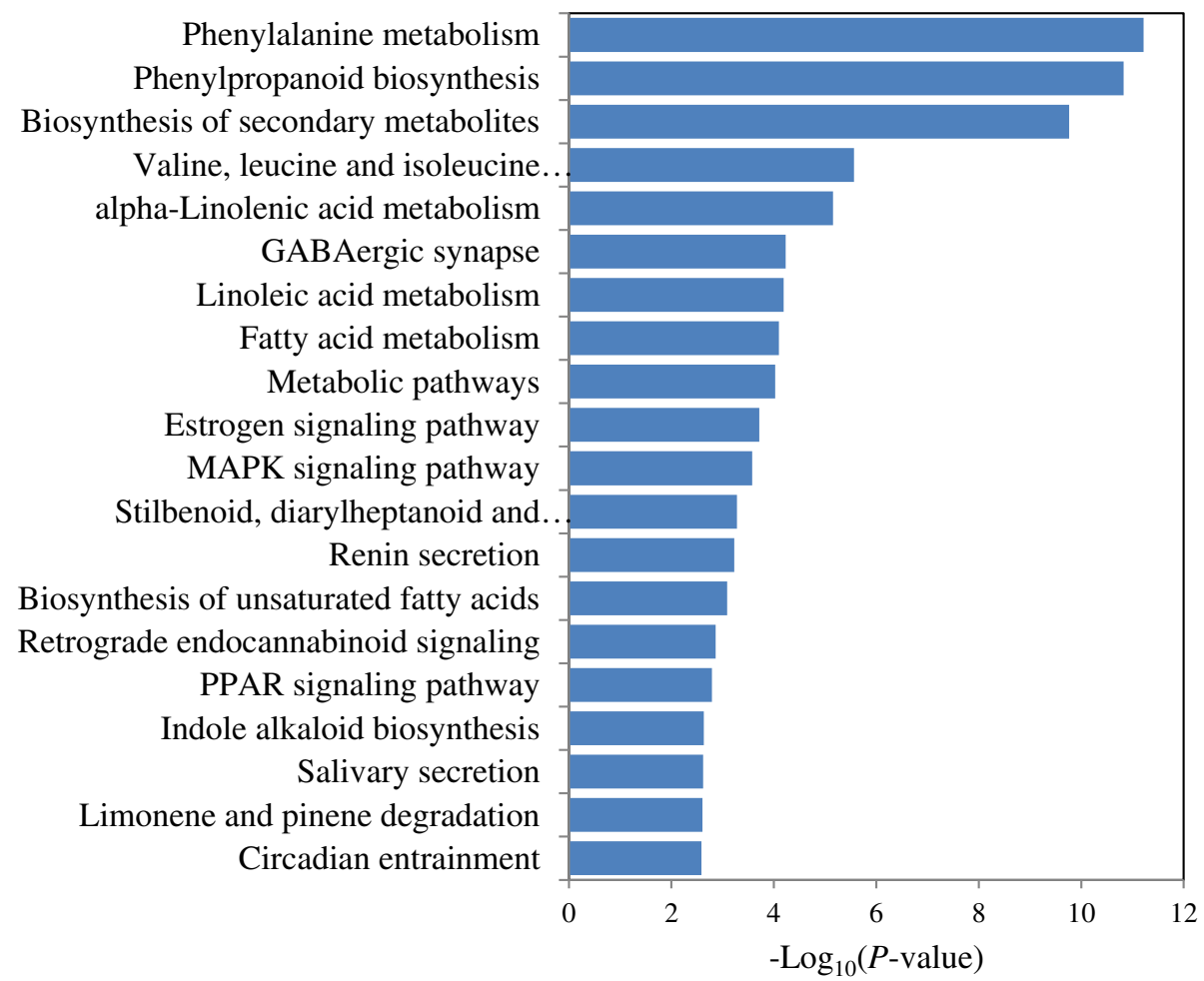

Fig. 2 The top 20 enriched KEGG pathways based on up-regulated DEGs in the T. longibrachiatum H9-inoculated plants in comparison to untreated plants (+T-B vs.-T-B) 


\section{KEGG pathways (Top 20)}

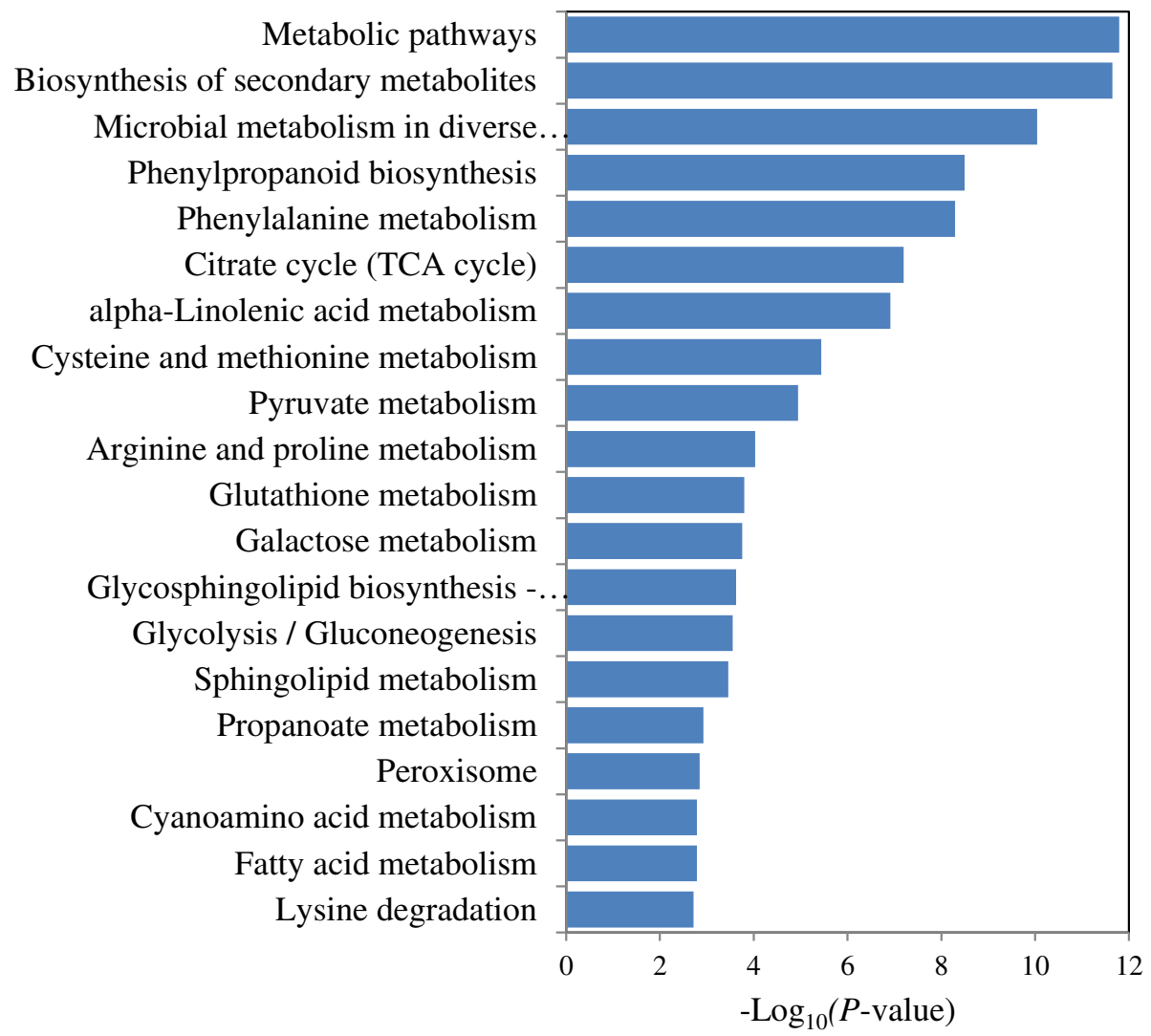

Fig. 3 The top 20 enriched KEGG pathways based on up-regulated DEPs in the T. longibrachiatum H9-inoculated plants in comparison to untreated plants (+T-B vs.-T-B)

initial Trichoderma-plant interaction and ISR-boost phase as the effects by Trichoderma on plant responses after subsequent challenge.

However, Shoresh et al. (2010) mentioned that the presence of non-pathogenic Trichoderma may prime the systemic resistance system, which means that the entire pathway may not be turned on constantly, and the plant will react more rapidly or more strongly in a subsequent pathogen infection. Specifically, the priming is not an universal phenomenon in all the Trichoderma-plant interactions, for example, T. harzianum T22 inoculation caused a constitutive turning on of some PR proteins in maize plants even without any pathogen [15, 48]. Applying specific inhibitors and analyzing the expression of key genes in the JA/ET signaling demonstrated that JA/ ET were involved in the protective effect triggered by $T$. asperellum T203 against $P$. syringae pv. Lachrymans. Remarkably, the Lox1, involved in JA production, was

Table 4 Correlation of DEGs and DEPs detected in the T. longibrachiatum H9-inoculated cucumber plants, compared to untreated plants (+T-B vs. -T-B)

\begin{tabular}{lll}
\hline Category & Genes & Proteins \\
\hline Total numbers of detected genes/Proteins & 20,189 & 4171 \\
Total number of corrected genes/Proteins & 3938 & 3938 \\
Total DEGs/DEPs & 3765 & 922 \\
DEGs/DEPs with corresponding proteins/genes & 798 & 835 \\
DEGs/ DEPs with corresponding DEPs/DEGs & 277 & 277 \\
Corrected DEGs/DEPs with the same expression trend & 241 out of 277 & 241 out of 277 \\
Corrected DEGs/DEPs with the opposite expression trend & 36 out of 277 & 36 out of 277 \\
\hline
\end{tabular}




\section{KEGG pathways (Top 20)}

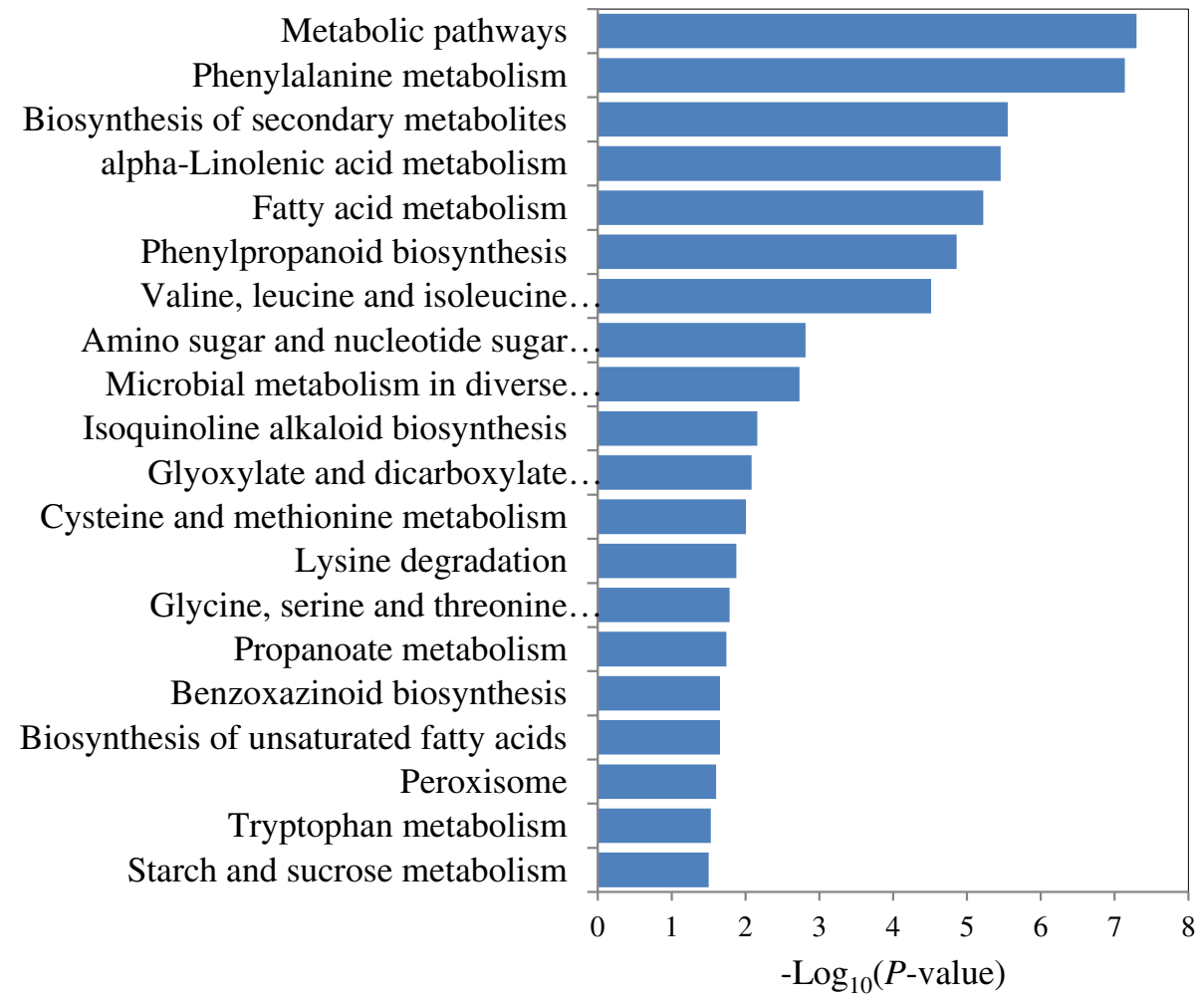

Fig. 4 The top 20 enriched KEGG pathways based on up-regulated corresponding DEGs/DEPs in the T. longibrachiatum H9-inoculated plants in comparison to untreated plants (+T-B vs.-T-B)

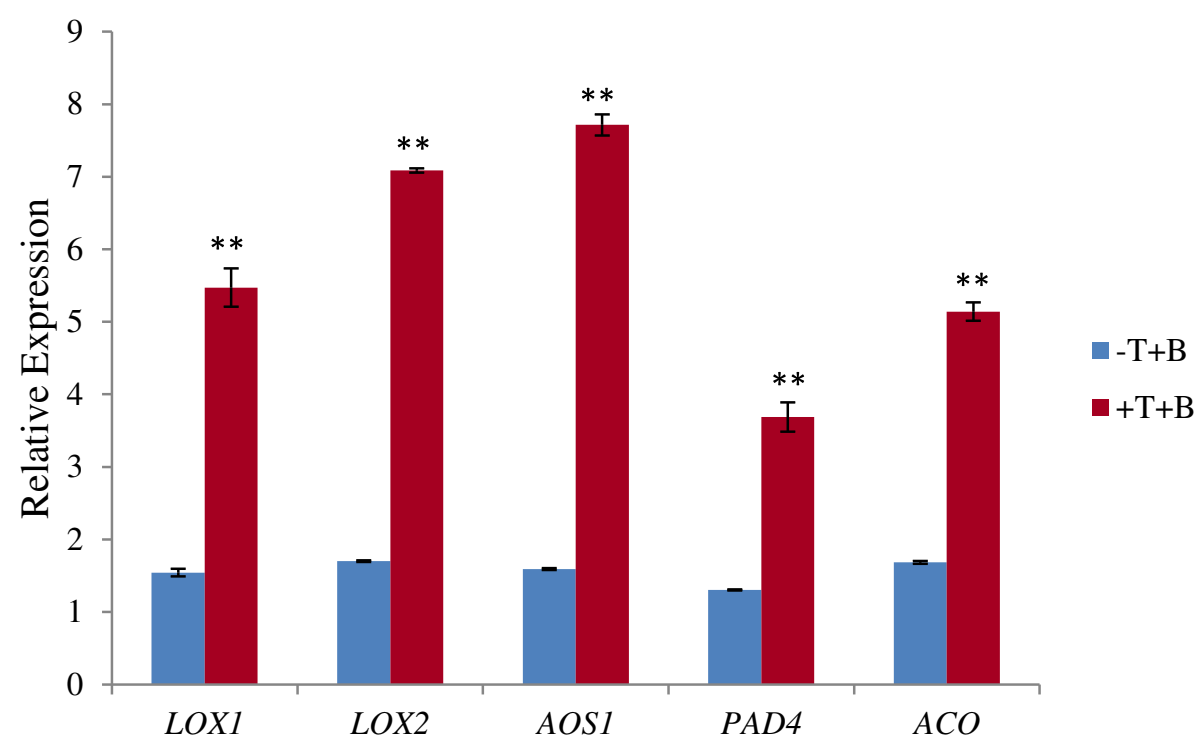

Fig. 5 The expression of hormone-related genes was up-regulated in cucumber plants inoculated with T. longibrachiatum H9. Among these expressed genes, LOX1, LOX2, and AOS1 were associated with JA; PAD4 was associated with SA; and ACO was associated with ET $*^{*}$ and ${ }^{* *}$ indicate significance at $P<0.05$ and 0.01 ) 
Table 5 The JA and SA contents in cucumber leaves significantly increased after inoculation of $T$. longibrachiatum $\mathrm{H} 9$ on the roots

\begin{tabular}{lll}
\hline Groups & SA $(\mathrm{ng} / \mathrm{g})$ & JA $(\mathrm{ng} / \mathrm{g})$ \\
\hline$-\mathrm{T}-\mathrm{B}$ & $104.24 \pm 0.3156$ & $89.48 \pm 0.5237$ \\
+T-B & $137.29 \pm 1.8120 * *$ & $151.45 \pm 0.0403 * *$ \\
\hline Note: * and ** indicate significance at $P<0.05$ and 0.01 &
\end{tabular}

hardly expressed in leaves and only clearly induced in roots with T. asperellum T203 inoculation before pathogen infection. In contrast, no difference of SA content in both roots and leaves were observed in the T. asperellum T203 pre-inoculated cucumber plants, regardless of whether the plants was infected with P. syringae pv. Lachrymans or not [10]. Our results showed that both JA/ET and SA production and/or signaling activation were observed as important plant responses in the Trichoderma-inoculated cucumber plants. Specifically, some points in our results differed from earlier findings: (i) the key components of the JA/ET and SA pathways were clearly detected in cucumber leaves and significantly up-regulated $96 \mathrm{~h}$ post $T$. longibrachiatum $\mathrm{H} 9$ inoculation without the subsequent infections, such as LOX (lipoxygenase), AOS (allene oxide synthase) and ACX (acyl-CoA oxidase) associated with JA synthesis, and metK (S-adenosylmethionine synthetase), ACS (aminocyclopropane carboxylate synthase) and ACO (aminocyclopropane carboxylate oxidase) associated with ET synthesis, as well as PAD4 (phytoalexin deficient 4) and PAL (phenylalanine ammonia-lyase) associated with SA synthesis. (ii) The expression of PALs rather than SID2/ICS2 was up-regulated at both gene and protein levels, indicating that SA was synthesized via the phenylalanine pathway rather than from chorismate pathway for $T$. longibrachiatum H9-induced ISR. The discrepancy among different researches suggested that the specific hormones involved may vary and behave differently in different plant-Trichoderma interactions, under different conditions and at different time points. However, the two points remain unknown in our study and require further investigation: (i) whether the additional pathogen $B$. cinerea challenge induces a higher plant response in the $T$. longibrachiatum H9-inoculated plants (whether the priming occurs or not), (ii) whether $B$. cinerea induces the plant response by itself or in the Trichoderma-mediated manner.

\section{Plants respond to Trichoderma by producing secondary metabolites}

The production of secondary metabolites, especially phytoalexins, is an important plant defense strategy against pathogens. Phenylpropanoid compounds are precursors to a wide range of antimicrobial phenolics, including lignins, flavonoids, isoflavonoids and cumarins. These compounds are induced in response to microbial attack and can inhibit the growth of attacking pathogens [3, 49].
The phenylpropanoid pathway is the major source of the production of antimicrobial phenolic compounds. Several genes of the phenylpropanoid pathway have been found to be up-regulated in A. thaliana after inoculation with T. asperelloides T203, including PAL1, PAL2 and $4 C L$ [26]. Camalexin, as an important secondary metabolite, accumulated in A. thaliana seedlings colonized with Trichoderma virens [29]. The biosynthesis of anthocyanins was increased in $A$. thaliana roots after inoculation of T. hamatum T382 [8]. In our results, the biosynthesis and metabolism processes of phenylpropanoid, flavonoid, lignin, coumarine, anthocyanin and some other secondary metabolites were activated, which implied that secondary metabolites play important roles for induced plant resistance in the $T$. longibrachiatum H9-inoculated cucumber plants.

Additionally, the antimicrobial activity of lipid transfer proteins (LTPs) in plant defense has also been reported against pathogens in numerous studies, probably due to their ability to interact with biological membranes, which may cause membrane permeabilization [50]. Proteome analysis and various transcriptome studies have also revealed altered expression of LTPs in plants inoculated with Trichoderma strains. In our study, lipid oxidation and lipid catabolic processes were also up-regulated in the $T$. longibrachiatum H9-inoculated cucumber plants, which indicated the possible importance of LTPs in the defense against $B$. cinerea in cucumber.

\section{A hypothetical working process in cucumber plants with T. longibrachiatum H9 inoculation}

MAMP (microbe-associated molecular pattern)-triggered immunity (MTI) and effector-triggered immunity (ETI) have been reported as two models of innate immunity in plants. Trichoderma can produce MAMPs as elicitors to activate plant defense responses. Plants deploy pattern recognition receptors (PRRs) to recognize the elicitors and activate a primary defense response [7, 41, 51-54]. Two MAMP/PRR pairs have been well characterized in Trichoderma spp. and plants. The first is ethylene-inducing-xylanase (Xyn2 or Eix) as the elicitor and its corresponding receptor EIX2 [55]. The second is chitin as the elicitor and its corresponding receptor CERK1 (chitin elicitor receptor-like kinase 1) [56]. Successful pathogens will deploy effectors to interfere with MTI and induce ETI which is based on the highly specific interaction of the pathogen effectors and their corresponding NB-LRR class receptors encoded by plant resistance $(R)$ genes. Several transcriptomic and proteomic studies have reported that plant interactions with various Trichoderma spp. resulted in the up-regulation of cytoplasmic NBS/leucine rich repeat receptors (NBS/ LRRs) [57, 58], suggesting that Trichoderma spp. can also induce ETI to activate plant defense. 


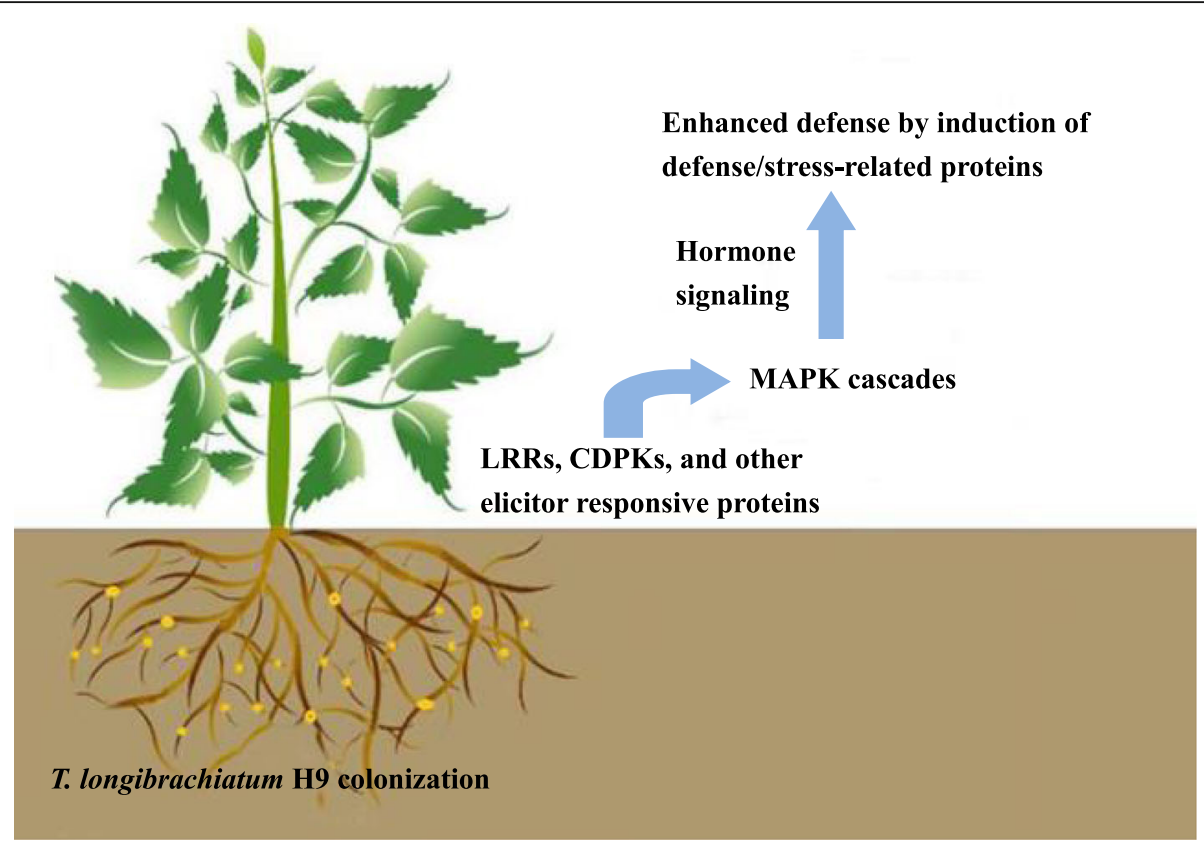

Fig. 6 A hypothetical working process in cucumber plants with T. longibrachiatum H9 inoculation. LRRs as well as CDPKs and other elicitor-responsive proteins were induced in the Trichoderma H9-inoculated cucumber plants to deliver the signal of perception. Subsequently, MAPK cascades were activated to regulate diverse downstream signaling pathways. Furthermore, phytohormone synthesis and signaling (JA/ET and SA) were activated to translate Trichoderma-induced signaling into the activation of effective defense responses. Consequently, a whole array of defense/stress-related genes and proteins, e.g. a variety of detoxifying enzymes for ROS scavenging, were up-regulated, thus rendering the cucumber plants more resistant to subsequent $B$. cinerea infection. Along with other defense strategies, the production of secondary metabolites was also employed as an important plant defense strategy

In our results, LRRs, CDPKs, calcium-transporting ATPases and some other elicitor-responsive proteins were up-regulated, which indicated that MTI and ETI immunity systems may exist in the $T$. longibrachiatum H9-inoculated cucumber plants. Moreover, a wide array of plant responses including the activation of MAPK signaling cascades, phytohormone responses, defense/ stress-related responses and the production of secondary metabolites, was discovered at the transcription and protein levels. Based on the results, we developed a hypothetical working model in which $T$. longibrachiatum $\mathrm{H} 9$ inoculation enhanced plant resistance in cucumber to effectively antagonize $B$. cinerea. Inoculation of $T$. longibrachiatum H9 to cucumber roots resulted in the induction of LRRs and CDPKs and other elicitor-responsive proteins, which are known as specific determinants of the plant immune response to deliver the signal of perception. Subsequently, MAPKs and WRKYs were activated as an early plant response. The induction of the MAPK signaling cascade is known to regulate diverse downstream signaling pathways and convert extracellular signals into intracellular responses [15]. Furthermore, the synthesis and signaling of phytohormones (JA/ET and SA) were activated to translate Trichoderma-induced signaling into the activation of effective defense responses. Consequently, a whole array of defense/ stress-related genes and proteins, e.g., several types of detoxifying enzymes for ROS scavenging were up-regulated in the cucumber leaves post $T$. longibrachiatum H9 inoculation of the roots, thus rendering the cucumber plants more resistant to subsequent $B$. cinerea attack. Along with other defense strategies, the production of secondary metabolites was also employed as an important plant defense strategy. Finally, these responses would provide cucumber plants with induced resistance to effectively decrease gray mold caused by B. cinerea (Fig. 6).

\section{Conclusions}

Root colonization of T. longibrachiatum H9 in the outer layer of epidermis effectively promoted plant growth and reduced the disease index of gray mold caused by $B$. cinerea in cucumber. Furthermore, the large-scale, multi-omics datasets indicated that $T$. longibrachiatum H9 inoculation modulated the defense network and resulted in an enhanced defensive capacity in cucumber plants, probably through the activation of signaling pathways associated with the phytohormones JA/ET and SA.

\section{Additional files}

Additional file 1: Table S1. The primer sequences for the PCR amplification. (DOC $58 \mathrm{~kb}$ ) 
Additional file 2: Table S2. Enriched GO terms based on up-regulated DEGs in the T. longibrachiatum H9-inoculated plants in comparison to untreated plants. (XLS $1111 \mathrm{~kb})$

Additional file 3: Table S3. Enriched GO terms based on up-regulated DEPs in the T. longibrachiatum H9-inoculated plants in comparison to untreated plants. (XLS $960 \mathrm{~kb}$ )

Additional file 4: Table S4. Enriched GO terms based on downregulated DEGs in the T. longibrachiatum $\mathrm{H} 9$-inoculated plants in comparison to untreated plants. (XLS $439 \mathrm{~kb}$ )

Additional file 5: Table S5. Enriched GO terms based on downregulated DEPs in the $\mathrm{T}$. longibrachiatum $\mathrm{H}$-inoculated plants in comparison to untreated plants. (XLS $459 \mathrm{~kb}$ )

Additional file 6: Table S6. Enriched KEGG pathways based on upregulated DEGs in the T. Iongibrachiatum $\mathrm{H}$-inoculated plants in comparison to untreated plants. (XLS $56 \mathrm{~kb}$ )

Additional file 7: Table S7. Enriched KEGG pathways based on upregulated DEPs in the T. longibrachiatum $\mathrm{H} 9$-inoculated plants in comparison to untreated plants. (XLS $51 \mathrm{~kb}$ )

Additional file 8: Table S8. The list of DEGs/DEPs with the same expression trends. (XLS $134 \mathrm{~kb}$ )

Additional file 9: Figure S1. The top 20 enriched KEGG pathways based on down-regulated DEGs/DEPs in the T. longibrachiatum H9inoculated plants in comparison to untreated plants (+T-B vs.-T-B). (DOCX $14 \mathrm{~kb})$

\section{Acknowledgements}

We thank Dr. Kyle Bender from TSL (The Sainsbury Laboratory) for the in-depth revision of the manuscript, and Dr. Jihong Xing from Hebei Agricultural University for the $B$. cinerea strain donation. We also would like to thank LetPub (www.letpub.com) for providing linguistic assistance.

\section{Consent to publication}

Not applicable

\section{Funding}

This work was financially supported by the Key Fundamental Research Program of Hebei Province (15962904D), the National Water Pollution Control and Treatment Science and Technology Major Project of China (2015ZX07204-007), and National Natural Science Foundation of China (31401212). The funders had no role in study design, data collection and analysis, decision to publish, or preparation of the manuscript.

\section{Availability of data and materials}

The data supporting the results of this study are included in the manuscript and additional supporting files. Raw data from transcriptome analysis by RNA-Seq have been deposited into the Sequence Read Archive database with the accession number SRP136435. Raw data from translatome analysis by ITRAQ mass spectrometry have been deposited into iProX (ww.iprox.org) with ID IPX0001185000/PXD009314.

\section{Authors' contributions}

YLH conceived and designed the project. MY and YYH performed the experiments. MY and YLH wrote the manuscript. WNG, ZHJ, SSS and LZ participated in data discussion and data analysis. All authors have read and approved the final manuscript.

\section{Ethics approval and consent to participate}

The authors confirm that the seeds of cucumber (Cucumis sativus L.) were purchased from Tianjin Kernel Cucumber Research Institute (Tianjin, China) All experiments were conducted in accordance with the local legislation for plant material handling.

\section{Competing interests}

The authors declare that there are no conflicts of interest.

\section{Publisher's Note}

Springer Nature remains neutral with regard to jurisdictional claims in published maps and institutional affiliations.

\section{Author details}

${ }^{1}$ College of Life Sciences, North China University of Science and Technology, Tangshan 063210, People's Republic of China. ${ }^{2}$ Biology Institute, Hebei Academy of Sciences, Shijiazhuang 050081, People's Republic of China.

Received: 29 August 2018 Accepted: 6 February 2019

Published online: 18 February 2019

\section{References}

1. Dean R, Van Kan JA, Pretorius ZA, Hammond-Kosack KE, Di Pietro A, Spanu PD, Rudd JJ, Dickman M, Kahmann R, Ellis J, Foster GD. The top 10 fungal pathogens in molecular plant pathology. Mol Plant Pathol 2012; 13(4):414-430.

2. Yun HG, Kim DJ, Gwak WS, Shin TY, Woo SD. Entomopathogenic Fungi as dual control agents against both the Pest Myzus persicae and Phytopathogen Botrytis cinerea. Mycobiology. 2017;45(3):192-8.

3. Harman GE, Howell CR, Viterbo A, Chet I, Lorito M. Trichoderma species-opportunistic, avirulent plant symbionts. Nat Rev Microbiol. 2004;2(1):43-56.

4. Glare TR, Gwynn RL, Moran-Diez ME. Development of biopesticides and future opportunities. Methods Mol Biol. 2016;1477:211-21.

5. Druzhinina IS, Seidl-Seiboth V, Herrera-Estrella A, Horwitz BA, Kenerley CM, Monte E, Mukherjee PK, Zeilinger S, Grigoriev IV, Kubicek CP. Trichoderma: the genomics of opportunistic success. Nat Rev Microbiol. 2011;9(10):749-59.

6. Mukherjee PK, Horwitz BA, Kenerley CM. Secondary metabolism in Trichoderma--a genomic perspective. Microbiology 2012; 158(Pt 1):35-45.

7. Vos CM, De Cremer K, Cammue BP, De Coninck B. The toolbox of Trichoderma spp. in the biocontrol of Botrytis cinerea disease. Mol Plant Pathol. 2015;16(4):400-12.

8. Mathys J, De Cremer K, Timmermans P, Van Kerckhove S, Lievens B, Vanhaecke M, Cammue BP, De Coninck B. Genome-wide characterization of ISR induced in Arabidopsis thaliana by Trichoderma hamatum T382 against Botrytis cinerea infection. Front Plant Sci. 2012;3:108.

9. Harel YM, Mehari ZH, Rav-David D, Elad Y. Systemic resistance to gray mold induced in tomato by benzothiadiazole and Trichoderma harzianum T39. Phytopathology. 2014;104(2):150-7

10. Shoresh M, Yedidia I, Chet I. Involvement of Jasmonic acid/ethylene signaling pathway in the systemic resistance induced in cucumber by Trichoderma asperellum T203. Phytopathology. 2005;95(1):76-84.

11. Alkooranee JT, Aledan TR, Ali AK, Lu G, Zhang X, Wu J, Fu C, Li M. Detecting the hormonal pathways in oilseed rape behind induced systemic resistance by Trichoderma harzianum TH12 to Sclerotinia sclerotiorum. PLoS One. 2017;12(1):e0168850

12. Brand M, Messika Y, Elad Y, David DR, Sztejnberg A. Spray treatments combined with climate modification for the management of Leveillula taurica in sweet pepper. Eur J Plant Pathol. 2009;124(2):309-29.

13. Shoresh M, Gal-On A, Leibman D, Chet I. Characterization of a mitogenactivated protein kinase gene from cucumber required for trichodermaconferred plant resistance. Plant Physiol. 2006;142(3):1169-79.

14. Rodriguez MC, Petersen M, Mundy J. Mitogen-activated protein kinase signaling in plants. Annu Rev Plant Biol. 2010;61:621-49.

15. Shoresh M, Harman GE, Mastouri F. Induced systemic resistance and plant responses to fungal biocontrol agents. Annu Rev Phytopathol. 2010;48:21-43.

16. Moran-Diez E, Rubio B, Dominguez S, Hermosa R, Monte E, Nicolas C. Transcriptomic response of Arabidopsis thaliana after $24 \mathrm{~h}$ incubation with the biocontrol fungus Trichoderma harzianum. J Plant Physiol. 2012;169(6): 614-20.

17. Van der Ent S, Van Wees SC, Pieterse CM. Jasmonate signaling in plant interactions with resistance-inducing beneficial microbes. Phytochemistry. 2009;70(13-14):1581-8.

18. Martinez-Medina A, Fernandez I, Sanchez-Guzman MJ, Jung SC, Pascual JA Pozo MJ. Deciphering the hormonal signalling network behind the systemic resistance induced by Trichoderma harzianum in tomato. Front Plant Sci. 2013;4:206.

19. Martinez-Medina A, Fernandez I, Lok GB, Pozo MJ, Pieterse CM, Van Wees SC. Shifting from priming of salicylic acid- to jasmonic acid-regulated 
defences by Trichoderma protects tomato against the root knot nematode Meloidogyne incognita. New Phytol. 2017;213(3):1363-77.

20. Segarra G, Van der Ent S, Trillas I, Pieterse CM. MYB72, a node of convergence in induced systemic resistance triggered by a fungal and a bacterial beneficial microbe. Plant Biol (Stuttg). 2009;11(1):90-6.

21. Mayo S, Gutierrez S, Malmierca MG, Lorenzana A, Campelo MP, Hermosa R, Casquero PA. Influence of Rhizoctonia solani and Trichoderma spp. in growth of bean (Phaseolus vulgaris L.) and in the induction of plant defense-related genes. Front Plant Sci. 2015;6:685.

22. Korolev N, Rav David D, Elad Y. The role of phytohormones in basal resistance and Trichoderma-induced systemic resistance to Botrytis cinerea in Arabidopsis thaliana. BioControl. 2008:53:667-83.

23. Leonetti P, Zonno MC, Molinari S, Altomare C. Induction of SA-signaling pathway and ethylene biosynthesis in Trichoderma harzianum-treated tomato plants after infection of the root-knot nematode Meloidogyne incognita. Plant Cell Rep. 2017;36(4):621-31.

24. Mur LA, Prats E, Pierre S, Hall MA, Hebelstrup KH. Integrating nitric oxide into salicylic acid and jasmonic acid/ ethylene plant defense pathways. Front Plant Sci. 2013;4:215.

25. Shoresh M, Harman GE. Differential expression of maize chitinases in the presence or absence of Trichoderma harzianum strain T22 and indications of a novel exo- endo-heterodimeric chitinase activity. BMC Plant Biol. 2010; 10:136.

26. Brotman Y, Landau U, Cuadros-Inostroza A, Tohge T, Fernie AR, Chet I, Viterbo A, Willmitzer L. Trichoderma-plant root colonization: escaping early plant defense responses and activation of the antioxidant machinery for saline stress tolerance. PLoS Pathog. 2013;9(3):e1003221.

27. Temme N, Tudzynski P. Does botrytis cinerea ignore $\mathrm{H}(2) \mathrm{O}(2)$-induced oxidative stress during infection? Characterization of botrytis activator protein 1. Mol Plant-Microbe Interact. 2009;22(8):987-98.

28. Chassot C, Buchala A, Schoonbeek HJ, Metraux JP, Lamotte O. Wounding of Arabidopsis leaves causes a powerful but transient protection against Botrytis infection. Plant J. 2008;55(4):555-67.

29. Velazquez-Robledo R, Contreras-Cornejo HA, Macias-Rodriguez L, Hernandez-Morales A, Aguirre J, Casas-Flores S, Lopez-Bucio J, HerreraEstrella A. Role of the 4-phosphopantetheinyl transferase of Trichoderma virens in secondary metabolism and induction of plant defense responses. Mol Plant-Microbe Interact. 2011;24(12):1459-71.

30. Contreras-Cornejo HA, Macias-Rodriguez L, Beltran-Pena E, Herrera-Estrella A, Lopez-Bucio J. Trichoderma-induced plant immunity likely involves both hormonal- and camalexin-dependent mechanisms in Arabidopsis thaliana and confers resistance against necrotrophic fungi Botrytis cinerea. Plant Signal Behav. 2011;6(10):1554-63.

31. Yedidia I, Shoresh M, Kerem Z, Benhamou N, Kapulnik Y, Chet I. Concomitant induction of systemic resistance to Pseudomonas syringae pv. Lachrymans in cucumber by Trichoderma asperellum (T-203) and accumulation of phytoalexins. Appl Environ Microbiol. 2003;69(12):7343-53.

32. Kim SH, Vujanovic V. Relationship between mycoparasites lifestyles and biocontrol behaviors against Fusarium spp. and mycotoxins production. Appl Microbiol Biotechnol. 2016;100(12):5257-72.

33. Pandey V, Ansari MW, Tula S, Yadav S, Sahoo RK, Shukla N, Bains G, Badal S, Chandra S, Gaur AK, Kumar A, Shukla A, Kumar J, Tuteja N. Dose-dependent response of Trichoderma harzianum in improving drought tolerance in rice genotypes. Planta. 2016;243(5):1251-64.

34. Nawrocka J, Malolepsza U, Szymczak K, Szczech M. Involvement of metabolic components, volatile compounds, PR proteins, and mechanical strengthening in multilayer protection of cucumber plants against Rhizoctonia solani activated by Trichoderma atroviride TRS25. Protoplasma. 2018;255(1):359-73.

35. Raza W, Ling N, Zhang R, Huang $Q, X u Y$, Shen Q. Success evaluation of the biological control of Fusarium wilts of cucumber, banana, and tomato since 2000 and future research strategies. Crit Rev Biotechnol. 2017;37(2):202-12.

36. Gams W, Morphology BJ. Identification of Trichoderma. In: Kubicek CP, Harman GE, editiors. Trichoderma and gliocladium, basic biology, taxonomy and genetics. Taylor and Francis Itd, London; 1998. p. 3-34.

37. Kumar S, Stecher G, Tamura K. MEGA7: molecular evolutionary genetics analysis version 7.0 for bigger datasets. Mol Biol Evol. 2016;33(7):1870-4.

38. Yedidia II, Benhamou N, Chet II. Induction of defense responses in cucumber plants (Cucumis sativus L.) by the biocontrol agent trichoderma harzianum. Appl Environ Microbiol 1999; 65(3):1061-1070.
39. Li Y, Sun R, Yu J, Saravanakumar K, Chen J. Antagonistic and biocontrol potential of Trichoderma asperellum ZJSX5003 against the maize stalk rot pathogen Fusarium graminearum. Indian J Microbiol. 2016;56(3):318-27.

40. Wang Z, Cui J, Song J, Gou M, Wang H, Gao K, Qiu X, Wang X, Chang Y. Integration of small RNAs and mRNAs by high-throughput sequencing reveals a complex regulatory network in Chinese sea cucumber, Russian sea cucumber and their hybrids. Comp Biochem Physiol Part D Genomics Proteomics. 2018;29:1-13.

41. Ye X, Wang H, Chen P, Fu B, Zhang M, Li J, Zheng X, Tan B, Feng J. Combination of ITRAQ proteomics and RNA-seq transcriptomics reveals multiple levels of regulation in phytoplasma-infected Ziziphus jujuba mill. Hortic Res. 2017:4:17080.

42. Norskov NP, Kyro C, Olsen A, Tjonneland A, Knudsen KE. High-throughput LC-MS/MS method for direct quantification of Glucuronidated, sulfated, and free Enterolactone in human plasma. J Proteome Res. 2016;15(3):1051-8.

43. Druzhinina IS, Komon-Zelazowska M, Kredics L, Hatvani L, Antal Z, Belayneh T, Kubicek CP. Alternative reproductive strategies of Hypocrea orientalis and genetically close but clonal Trichoderma longibrachiatum, both capable of causing invasive mycoses of humans. Microbiology 2008; 154(Pt 11):3447-3459.

44. Jaklitsch WM, Voglmayr H. Hypocrea britdaniae and H. Foliicola: two remarkable new European species. Mycologia. 2012;104(5):1213-21.

45. Kredics L, Kocsube S, Nagy L, Komon-Zelazowska M, Manczinger L, Sajben E, Nagy A, Vagvolgyi C, Kubicek CP, Druzhinina IS, Hatvani L. Molecular identification of Trichoderma species associated with Pleurotus ostreatus and natural substrates of the oyster mushroom. FEMS Microbiol Lett. 2009; 300(1):58-67.

46. Jaklitsch WM. European species of Hypocrea part I. The green-spored species. Stud Mycol. 2009;63:1-91.

47. Jaklitsch WM. European species of Hypocrea part II: species with hyaline ascospores. Fungal Divers. 2011;48(1):1-250.

48. Shoresh M, Harman GE. The molecular basis of shoot responses of maize seedlings to Trichoderma harzianum T22 inoculation of the root: a proteomic approach. Plant Physiol. 2008;147(4):2147-63.

49. Huang J, Gu M, Lai Z, Fan B, Shi K, Zhou YH, Yu JQ, Chen Z. Functional analysis of the Arabidopsis PAL gene family in plant growth, development, and response to environmental stress. Plant Physiol. 2010;153(4):1526-38.

50. Sels J, Mathys J, De Coninck BM, Cammue BP, De Bolle MF. Plant pathogenesis-related (PR) proteins: a focus on PR peptides. Plant Physiol Biochem. 2008:46(11):941-50.

51. Zipfel C, Kunze G, Chinchilla D, Caniard A, Jones JD, Boller T, Felix G. Perception of the bacterial PAMP EF-Tu by the receptor EFR restricts agrobacterium-mediated transformation. Cell. 2006;125(4):749-60.

52. Svoboda J, Boland W. Plant defense elicitors: analogues of jasmonoylisoleucine conjugate. Phytochemistry. 2010;71(13):1445-9.

53. Pare PW, Farag MA, Krishnamachari V, Zhang H, Ryu CM, Kloepper JW. Elicitors and priming agents initiate plant defense responses. Photosynth Res. 2005;85(2):149-59.

54. Sarrocco S, Matarese F, Baroncelli R, Vannacci G, Seidl-Seiboth V, Kubicek CP, Vergara M. The constitutive Endopolygalacturonase TVPG2 regulates the induction of plant systemic resistance by Trichoderma virens. Phytopathology. 2017;107(5):537-44.

55. Hanson LE, Howell CR. Elicitors of plant defense responses from biocontrol strains of Trichoderma viren. Phytopathology. 2004;94(2):171-6.

56. Petutschnig EK, Jones AM, Serazetdinova L, Lipka U, Lipka V. The lysin motif receptor-like kinase (LysM-RLK) CERK1 is a major chitin-binding protein in Arabidopsis thaliana and subject to chitin-induced phosphorylation. J Biol Chem. 2010;285(37):28902-11.

57. Palmieri MC, Perazzolli M, Matafora V, Moretto M, Bachi A, Pertot I. Proteomic analysis of grapevine resistance induced by Trichoderma harzianum T39 reveals specific defence pathways activated against downy mildew. J Exp Bot. 2012;63(17):6237-51.

58. Perazzolli M, Moretto M, Fontana P, Ferrarini A, Velasco R, Moser C, Delledonne M, Pertot I. Downy mildew resistance induced by Trichoderma harzianum T39 in susceptible grapevines partially mimics transcriptional changes of resistant genotypes. BMC Genomics. 2012;13:660. 